\title{
Upregulation of miR-185 promotes apoptosis of the human gastric cancer cell line MGC803
}

\author{
LIQIAO FAN, BIBO TAN, YONG LI, QUN ZHAO, HUFANG YUAN, YU LIU, \\ DONG WANG and ZHIDONG ZHANG
}

\begin{abstract}
Department of General Surgery, The Fourth Affiliated Hospital, Hebei Medical University, Shijiazhuang, Hebei 050011, P.R. China
\end{abstract}

Received June 24, 2016; Accepted May 5, 2017

DOI: $10.3892 / \mathrm{mmr} .2017 .8206$

\begin{abstract}
MicroRNA (miR)-185, which has been reported to be abnormally expressed in some types of cancer, exerts significant effects on the proliferation, apoptosis, drug resistance and metastasis of cancer cells. The present study aimed to explore the effects and underlying molecular mechanisms of miR-185 upregulation on the apoptosis of gastric cancer (GC) cells. Quantitative polymerase chain reaction (qPCR) and western blotting were used to detect the expression levels of miR-185 in GC and adjacent normal tissues. In addition, miR-185 expression was detected in the following GC cell lines: MKN74, SGC7901, BGC823, MGC803, as well as in the gastric epithelial cell line GES-1. Subsequently, miR-185 mimics were transfected into MGC803 cells. Post-transfection, the following experiments were conducted: MTT assay was applied to test cell viability; flow cytometry (FCM) was used to determine the apoptotic rate of the cells; and qPCR and western blotting were conducted to detect the expression levels of the following apoptosis-associated factors: B-cell lymphoma 2 (Bcl-2), Bcl-2-associated X protein (Bax), survivin, X-linked inhibitor of apoptosis protein (XIAP), livin, caspase- 3 and caspase- 8 . The results demonstrated that miR-185 was downregulated in GC tissues compared with the adjacent tissues. In cell lines, miR-185 expression was higher in GES-1 cells compared with in the GC cell lines; in the 4 GC cell lines, the strongest miR-185 expression was in MKN74 cells, followed by SGC7901 and BGC823 cells, and the weakest was in MGC803 cells $(\mathrm{P}<0.05)$. Expression of miR-185 was associated with tumor size, differentiation and lymphatic metastasis. Post-transfection with miR-185 mimics, miR-185 expression was significantly increased in a time- and concentration-dependent manner. MGC803 cell viability was
\end{abstract}

Correspondence to: Dr Yong Li, Department of General Surgery, The Fourth Affiliated Hospital, Hebei Medical University, 12 Jian-kang Road, Shijiazhuang, Hebei 050011, P.R. China

E-mail: li_yong_hbth@126.com

Key words: gastric cancer, microRNA-185, apoptosis, apoptosis-associated genes, caspase- 3 , caspase- 8 significantly decreased following miR-185 mimics transfection. The results of FCM demonstrated that post-transfection with miR-185 mimics, the apoptotic rate of MGC803 cells was significantly increased. Post-transfection with miR-185 mimics, the expression levels of Bcl-2, survivin and XIAP were significantly decreased in MGC803 cells, whereas the expression levels of Bax and livin were not altered, and caspase- 3 and caspase- 8 expression was significantly increased. Spectrophotometry indicated that caspase-3 and caspase- 8 activity was significantly increased in MGC803 cells following transfection with miR-185 mimics. In conclusion, the present study suggested that miR-185 upregulation in GC cells may promote apoptosis of tumor cells via gene expression regulation.

\section{Introduction}

Gastric cancer (GC) is the most common gastrointestinal malignancy in Asia (1). With the advancement of diagnostic and therapeutic techniques, certain preventative measures and treatment strategies have been developed, thus resulting in a decline in GC incidence and mortality rate. However, GC remains a serious threat to human health (2-5). During the complex development and progression of GC, various molecules have been confirmed to be involved in tumor cell proliferation, apoptosis, invasion, metastasis and drug resistance $(6,7)$. Although numerous studies have been conducted regarding $\mathrm{GC}$, the exact molecular mechanisms underlying GC remain unclear $(8,9)$. In recent studies, apoptotic resistance has been suggested as an important feature of GC cells (10). Due to their marked anti-apoptotic activity, GC cells exhibit strong survivability, which may lead to the progression and metastasis of GC. It has previously been confirmed that some molecules and signaling pathways are involved in the development of apoptotic resistance in GC (11-13); however, the key molecules and signaling pathways remain to be elucidated.

The complex molecular mechanisms underlying apoptotic resistance of GC cells have been explored in numerous studies (14-16); however, these studies have been unsuccessful in applying apoptosis-promoting strategies in the treatment of GC. Previous studies demonstrated that microRNAs (miRNAs/miR) serve a regulatory role in the apoptosis of GC cells $(17,18)$. Since miRNAs exert a potent inhibitory effect on 
numerous target genes, they are considered to possess a stronger biological function compared with single genes. Numerous studies have reported that miR-185 is involved in tumor proliferation, apoptosis, invasion and multidrug resistance (19-21). miR-185 may also be involved in the apoptosis of GC cells; however, the association between miR-185 and GC cell apoptosis, as well as the underlying molecular mechanisms, remain unclear. The present study analyzed the association between miR-185 and apoptosis of GC cells, and demonstrated that miR-185 expression was significantly decreased in GC tissues and cell lines; in particular, miR-185 expression was lower in poorly differentiated cell lines. Following transfection with miR-185 mimics, in order to upregulate miR-185 expression in GC cells, the viability of GC cells was significantly decreased; apoptotic rate was increased; and the expression levels of apoptosis-associated genes [B-cell lymphoma 2 (Bcl-2), survivin, $\mathrm{X}$-linked inhibitor of apoptosis protein (XIAP)], and the expression and activity of caspase- 3 and caspase- 8 were altered. These results suggested that miR-185 was associated with apoptosis of GC cells by downregulating the expression of anti-apoptotic genes. miR-185 may promote apoptosis of GC cells; therefore, miR-185 may serve as a tumor marker and as a potential target for the regulation of GC cell apoptosis.

\section{Materials and methods}

Materials. Human GC cell lines MKN74, SGC7901, BGC823 and MGC803 were obtained from the Research Center of the Fourth Affiliated Hospital of Hebei Medical University (Shijiazhuang, China); and the GES-1 gastric epithelial cell line was purchased from the Institute of Biochemistry and Cell Biology (Shanghai, China). RPMI-1640 culture medium and trypsin were purchased from Gibco (Thermo Fisher Scientific, Inc., Waltham, MA, USA); TRIzol reagent and Lipofectamine $^{\mathrm{TM}} 2000$ transfection reagents were purchased from Invitrogen (Thermo Fisher Scientific, Inc.). Reverse transcription (RT) kit and fluorescence RT-quantitative polymerase chain reaction (qPCR) reagents were purchased from Promega Corporation (Madison, WI, USA); PCR primers and miR-185 mimics were synthesized by Sangon Biotech Co., Ltd. (Shanghai, China). Protein extraction kit was purchased from Beyotime Institute of Biotechnology (Haimen, China); Bcl-2 (cat. no. sc-23960), Bcl-2-associated $\mathrm{X}$ protein (Bax) (cat. no. sc-7480), survivin (cat. no. sc-17779), XIAP (cat. no. sc-55551), livin (cat. no. sc-393237), caspase-3 (cat. no. sc-7272), caspase-8 (cat. no. sc-5263) and $\beta$-actin (cat. no. sc-8432) antibodies were all purchased from Santa Cruz Biotechnology, Inc. (Dallas, TX, USA). MTT was purchased from Sigma-Aldrich (Merck KGaA, Darmstadt, Germany). Caspase-3 (cat. no. G015) and caspase-8 (cat. no. G017) Activity Colorimetric Assay kits were purchased from Nanjing KeyGen Biotech Co., Ltd. (Nanjing, China).

Clinical sample preparations. The present study was approved by the Ethics Committee of the Fourth Affiliated Hospital, Hebei Medical University, and all patients provided written informed consent. A total of 30 patients with GC (21 males and 9 females; average age, 58.45 \pm 14.1 years), which had been surgically removed and pathologically confirmed, were recruited from the Fourth Affiliated Hospital of Hebei
Medical University. None of the patients received preoperative radiotherapy or chemotherapy. Specimens $(\sim 1.0 \times 0.5 \times 0.5 \mathrm{~cm})$, including cancerous and adjacent tissues $(>3 \mathrm{~cm}$ from the edge of cancerous tissue, no cancer cells present), were harvested and stored at $-80^{\circ} \mathrm{C}$.

Cell culture. MKN74, SGC7901, BGC823, MGC803 and GES-1 cells were cultured in RPMI-1640 containing $10 \%$ fetal calf serum (both from Gibco; Thermo Fisher Scientific, Inc.), $100 \mathrm{U} / \mathrm{ml}$ penicillin and $100 \mathrm{mg} / \mathrm{ml}$ streptomycin. The cells were incubated at $37^{\circ} \mathrm{C}$ in an atmosphere containing $5 \% \mathrm{CO}_{2}$. Cells were trypsinized in a $0.25 \%$ trypsin solution containing $0.02 \%$ of EDTA.

Synthesis and transfection of miR-185 mimics. Prior to transfection, miR-185 synthetic mimics (has-miR-185-5p-mimic, 5'-UGGAGAGAAAGGCAGUUCCUGA-3'; has-miR-185-5p inhibitor, 5'-ACCUCUCUUUCCGUCAAGGACU-3'; Guangzhou RiboBio Co., Ltd., Guangzhou, China) were dissolved at a concentration of $20 \mu \mathrm{mol} / 1$. MGC803 cells were seeded in 6-well plates at a density of $4 \times 10^{5}$ cells $/ \mathrm{ml}$, incubating at $37^{\circ} \mathrm{C}$ for $24 \mathrm{~h}$. Prior to transfection, cells were rinsed with RPMI-1640 medium free of serum and antibiotics. According to the manufacturer's instructions, untransfected control group and miR-185 mimics diluted with RPMI-1640 medium were mixed with Lipofectamine ${ }^{\circledR} 2000$. miR-185 mimics were then transfected into MGC803 cells. After $24 \mathrm{~h}$, he transfection efficiency was determined, and subsequent experiments were conducted after another $24 \mathrm{~h}$.

MTT assay to determine cell viability. MGC803 cells were seeded in $96-$-well plates at a density of $5 \times 10^{4}$ cells $/ \mathrm{ml}$. Cells at 60-70\% confluence were transfected with miR-185 mimics, or with only the negative transfection reagent Lipofectamine $^{\mathrm{TM}}$ 2000. A total of six replicates per group were analyzed. A total of $4 \mathrm{~h}$ prior to the end of the experiment, $20 \mu \mathrm{l}$ MTT $(5 \mathrm{mg} / \mathrm{ml})$ was added to each group. The cells were cultured at $37^{\circ} \mathrm{C}$ for $4 \mathrm{~h}$, and the culture medium was then discarded. Subsequently, $150 \mu 1$ dimethyl sulfoxide was added to each well and the plates were agitated at room temperature for $15 \mathrm{~min}$. Absorbance (A value) was then measured at a wavelength of $490 \mathrm{~nm}$; A value represented cell viability. This experiment was repeated three times at 24,48 and $72 \mathrm{~h}$.

Flow cytometry to detect apoptotic rate of GC cells. Apoptosis was quantified using an Annexin V-fluorescein isothiocyanate (FITC)/propidium iodide (PI) detection kit (Invitrogen; Thermo Fisher Scientific, Inc.), according to the manufacturer's instructions. Briefly, cells were harvested and resuspended in binding buffer $\left(10^{6}\right.$ cells $\left./ \mathrm{ml}\right)$. Following the addition of $5 \mu \mathrm{l}$ Annexin V-FITC and $10 \mu \mathrm{l}$ PI, the cells were mixed and were incubated for $15 \mathrm{~min}$ at room temperature in the dark. Annexin V-FITC binding was detected using a FACSCalibur flow cytometer (BD Biosciences, Franklin Lakes, NJ, USA). Data were analyzed using Cell Quest software 5.1 (BD Biosciences). The experiment was repeated three times.

Caspase- 3 and caspase- 8 activity assay. According to the protocol of the spectrophotometric detection kit, cells were collected, and lysed in $50 \mu \mathrm{l}$ cold lysis buffer for $20 \mathrm{~min}$. The 
cells were were centrifugated at $12,500 \mathrm{~g}$ for $10 \mathrm{~min}$, after which the supernatant was transferred to new tubes and the protein concentration of the cell lysates was measured by Bio-Rad DC ${ }^{\text {тм }}$ Protein Assay (Bio-Rad Laboratories, Inc., Hercules, CA, USA). Protein (100 $\mu \mathrm{g})$ was taken from each group and was adjusted to $50 \mu \mathrm{l}$ with lysis buffer. A total of $50 \mu \mathrm{l} 2 \mathrm{X}$ Reaction Buffer and $5 \mu \mathrm{l}$ appropriate substrate was added to each sample and was incubated at $37^{\circ} \mathrm{C}$ in the dark for $4 \mathrm{~h}$. Subsequently, A value was measured at a wavelength of $405 \mathrm{~nm}$ using a microplate reader. Caspase enzyme activity within a unit volume of protein represented caspase- 3 and caspase- 8 activation.

RNA isolation and RT-qPCR to detect target mRNA expression. Total RNA was extracted from cells and tissues, using the TRIzol one-step method and $2 \mu \mathrm{g}$ RNA was reverse transcribed to cDNA. cDNA $(2 \mu \mathrm{l})$ underwnt PCR to detect the mRNA expression of target molecules. GAPDH served as an internal reference gene. According to the manufacturer's instructions, PCR was conducted in a final volume of $20 \mu \mathrm{l}$, as follows: $2 \mu \mathrm{l}$ cDNA, $10 \mu 1$ SYBR Green Mix (Promega Corporation, Madison, WI, USA), and $0.5 \mu 1$ downstream and upstream primers $(10 \mu \mathrm{mol} / \mathrm{l}), 7 \mu \mathrm{l}$ deionized water. The following cycling conditions were conducted: 1 cycle at $95^{\circ} \mathrm{C}$ for $5 \mathrm{~min}$, followed by 45 cycles of $94^{\circ} \mathrm{C}$ for $30 \mathrm{sec}, 60^{\circ} \mathrm{C}$ for $30 \mathrm{sec}$, and $72^{\circ} \mathrm{C}$ for $30 \mathrm{sec}$, and a final extension at $72^{\circ} \mathrm{C}$ for $10 \mathrm{~min}$ ). Primers were designed using Primer 5.0 software (Premier Biosoft International, Palo Alto, CA, USA) and were detected for specificity using primer-BLAST (https://www.ncbi.nlm.nih. gov/tools/primer-blast/). Primer sequences for each gene were as follows: miR-185-5p forward, 5'-TCCGCTG GAGAGAAA GGC-3' and reverse, 5'-ATGGAGGCTGAGGAGCACTG-3'; Bcl-2 (98 bp) forward, 5'-TGTGTGGAGAGCGTCAACC-3' and reverse, 5'-TGGATCCAGGTGTGCAGGT-3'; Bax (129 bp) forward, 5'-TTTCTGACGGCAACTTCAA-3' and reverse, 5'-AGTCCAATGTCCAGCCCAT-3'; survivin (185 bp) forward, 5'-GCCAGATTTGAATCGCGGGA-3' and reverse, 5'-GCA GTGGATGAAGCCAGCCT-3'; XIAP (292 bp) forward, 5'-CCGTGCGGTGCTTTAGTTGT-3' and reverse, 5'-TTCC TCGGGTATATGGTGTCTGAT-3'; livin (312 bp) forward, 5'-TCCACAGTGTGCAGGAGACT-3' and reverse, 5'-ACGG CACAAAGACGATGGAC-3'; caspase-3 (148 bp) forward, 5'-AGAGCTGGACTGCGGTATTGAG-3' and reverse, 5'-GA ACCATGACCCGTCCCTTG-3'; caspase-8 (163 bp) forward, 5'-GATGAGGCAGACTTTCTGCT-3' and reverse, 5'-CAT AGTTCACGCCAGTCAGGAT-3'; and GAPDH (138 bp) forward, 5'-GACCCCTTCATTGACCTCAAC-3' and reverse, 5'-CGCTCCTGGAAGATGGTGAT-3'. qPCR results were analyzed using the $2^{-\Delta \Delta \mathrm{Cq}}$ method (22). GAPDH was used as an internal reference.

Western blot anlaysis of target proteins. Cell samples were lysed with lysis buffer: $1 \%$ Triton X-100, $150 \mathrm{mM} \mathrm{NaCl}$, $10 \mathrm{mM}$ Tris- $\mathrm{HCl}$ (pH 7.4), 1 mM EDTA, 1 mM EGTA (pH 8.0), $0.2 \mathrm{mM} \mathrm{Na}_{3} \mathrm{VO}_{4}, 0.2 \mathrm{mM}$ phenylmethylsulfonyl fluoride and $0.5 \%$ NP-40. Following protein quantification detected by Bicinchoninic acid Protein Quantitation kit (MultiSciences Biotech Co., Ltd., Hangzhou, China), $40 \mu \mathrm{g}$ protein from each sample were separated by $10 \%$ SDS-PAGE and were electrotransferred onto polyvinylidene fluoride
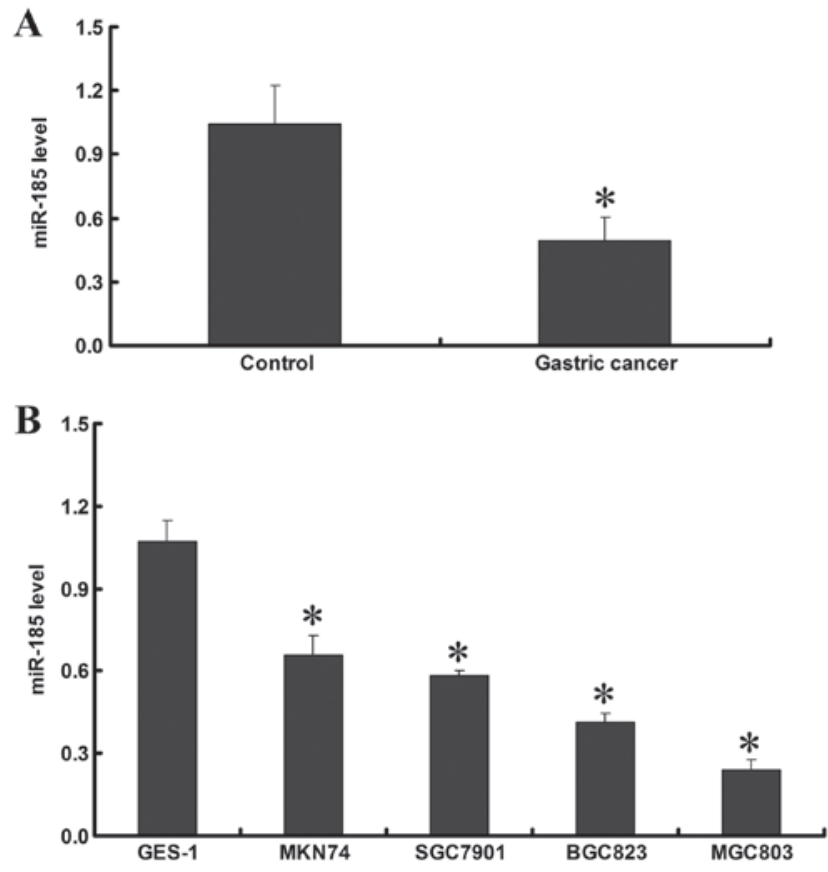

Figure 1. Expression of miR-185 in GC tissues and cell lines. (A) miR-185 expression was lower in GC tissues compared with in adjacent noncancerous tissues (control group), as determined by quantitative polymerase chain reaction. ${ }^{*} \mathrm{P}<0.05$ vs. the control group. (B) In the cell lines, miR-185 expression was lower in GC cell lines compared with in the GES-1 norma gastric epithelial cell line. The lowest miR-185 expression was detected in the MGC803 cell line. ${ }^{*} \mathrm{P}<0.05$ vs. the GES-1 cell line. GC, gastric cancer; miR-185, microRNA-185.

membranes (GE Healthcare Life Sciences, Little Chalfont, UK). Membranes were blocked with $5 \%$ bovine serum albumin (Sigma-Aldrich, Merck KGaA) at room temperature for $2 \mathrm{~h}$, and were incubated with primary antibodies (all 1:1,000) overnight at $4^{\circ} \mathrm{C}$. Membranes were then incubated at room temperature for $2 \mathrm{~h}$ with anti-mouse horseradish peroxidase-conjugated secondary antibody (1:10 ${ }^{5}$ ) (cat. no. 610-103-121-0100; Rockland Immunochemicals Inc., Pottstown, PA, USA) and target bands were detected using an enhanced chemiluminescence detection kit (Santa Cruz Biotechnology, Inc.). $\beta$-actin was used as the internal control. The experiment was repeated three times.

Statistical analysis. SPSS software version 16.0 (SPSS, Inc., Chicago, IL, USA) was used to analyze data. Experimental data were expressed as the mean \pm standard deviation $(n \geq 3)$. Data were analyzed by one-way analysis of variance sand Dunnett post hoc test. $\mathrm{P}<0.05$ was considered to indicate a statistically significant difference.

\section{Results}

miR-185 expression in GC tissues and cell lines. RT-qPCR demonstrated that miR-185 expression in GC tissues was lower than in adjacent noncancerous tissues $(\mathrm{P}<0.05$; Fig. 1A). In addition, the expression of miR-185 was detected in the cell lines, and the results demonstrated that miR-185 expression in GC cell lines was lower than in the GES-1 normal gastric epithelial cell line $(\mathrm{P}<0.05)$. In the GC cell lines, miR-185 expression was the highest in MKN74, followed by SGC7901 and BGC823, and 
Table I. Association of miR-185 expression with clinical characteristics of patients with GC.

\begin{tabular}{|c|c|c|c|c|}
\hline Characteristic & $\mathrm{n}$ & $\begin{array}{l}\mathrm{R}-185 \text { expression } \\
\text { in GC tissues }\end{array}$ & t-value & P-value \\
\hline Sex & & & -0.123 & 0.903 \\
\hline Male & 21 & $0.490 \pm 0.166$ & & \\
\hline Female & 9 & $0.498 \pm 0.155$ & & \\
\hline Age (years) & & & 0.170 & 0.866 \\
\hline$\geq 60$ & 9 & $0.500 \pm 0.177$ & & \\
\hline$<60$ & 21 & $0.489 \pm 0.156$ & & \\
\hline Tumor size $(\mathrm{cm})$ & & & -2.318 & 0.028 \\
\hline$\geq 5$ & 22 & $0.453 \pm 0.159$ & & \\
\hline$<5$ & 8 & $0.596 \pm 0.116$ & & \\
\hline Tumor-node-metastasis stage & & & -0.270 & 0.789 \\
\hline I-II & 7 & $0.478 \pm 0.054$ & & \\
\hline III-IV & 23 & $0.497 \pm 0.182$ & & \\
\hline Differentiation & & & 5.958 & $<0.001$ \\
\hline High/moderate & 21 & $0.572 \pm 0.126$ & & \\
\hline Poor/undifferentiated & 9 & $0.316 \pm 0.032$ & & \\
\hline Lymphatic metastasis & & & -4.032 & $<0.001$ \\
\hline Positive & 24 & $0.443 \pm 0.142$ & & \\
\hline Negative & 6 & $0.681 \pm 0.030$ & & \\
\hline
\end{tabular}

GC, gastric cancer; miR-185, microRNA-185.

the lowest miR-185 expression was detected in the MGC803 cell line $(\mathrm{P}<0.05$; Fig. 1B). These data indicated that miR-185 expression in GC tissues and cell lines is decreased, which may be associated with the development and progression of GC.

Association between miR-185 expression and clinicopathological characteristics. The present study demonstrated that miR-185 expression was not significantly correlated with gender $(\mathrm{t}=-0.123, \mathrm{P}=0.903)$, age $(\mathrm{t}=0.170, \mathrm{P}=0.866)$ or tumor-node-metastasis stage $(\mathrm{t}=-0.270, \mathrm{P}=0.789)$. However, miR-185 expression was correlated with tumor size, differentiation and lymphatic metastasis. miR-185 expression was reduced in tumors $\geq 5 \mathrm{~cm}$ compared with in tumors $<5 \mathrm{~cm}$ $(\mathrm{t}=-2.318, \mathrm{P}=0.028)$. In addition, miR-185 expression was decreased in poorly differentiated/undifferentiated tumors $(\mathrm{t}=5.958, \mathrm{P}<0.001)$, whereas $\mathrm{miR}-185$ expression was significantly higher in GC patients without lymph node metastasis compared with in patients with lymph node metastasis $(\mathrm{t}=-4.032, \mathrm{P}<0.001)$ (Table I).

Effects of miR-185 mimics on miR-185 expression in MGC803 cells. Post-transfection of MGC803 cells with $80 \mathrm{nM}$ miR-185 mimics for $24 \mathrm{~h}$, level of miR-185 in transfected cells was $107.85 \pm 19.58$, which in untransfected cells was $2.48 \pm 0.41$, and miR-185 expression was significantly increased $(\mathrm{P}<0.001)$, which provided a promising basis for further study of miR-185 function in $\mathrm{GC}$.

Effects of miR-185 mimics on MGC803 cell viability. The results of an MTT assay indicated that, post-transfection of

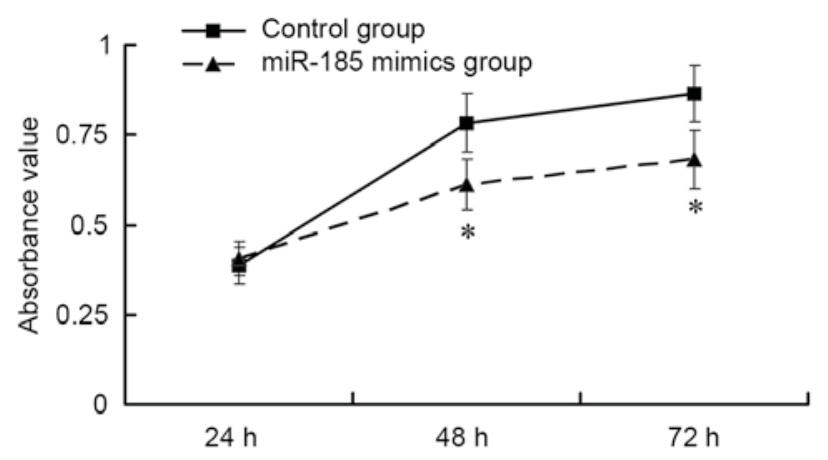

Figure 2. Effects of miR-185 mimics on MGC803 cell viability, as determined by MTT assay. Post-transfection of MGC803 cells with $80 \mathrm{nM}$ miR-185 mimics, viability was significantly reduced compared with in the control group, in a time-dependent manner. Data are presented as the mean \pm standard deviation ( $n=6 /$ group). ${ }^{*} \mathrm{P}<0.01$ vs. the control group. miR-185, microRNA-185.

MGC803 cells with $80 \mathrm{nM}$ miR-185 mimics, GC cell viability was significantly suppressed compared with in the control group in a time-dependent manner $(\mathrm{P}<0.01$; Fig. 2$)$. These findings indicated that upregulation of miR-185 may inhibit the viability of GC cells.

Effects of miR-185 mimics on MGC803 apoptosis. The results of FCM demonstrated that $48 \mathrm{~h}$ post-transfection of MGC803 cells with $80 \mathrm{nM}$ miR-185 mimics, the apoptotic rate of GC cells was significantly increased compared with in the control group $(\mathrm{P}<0.01$; Fig. 3$)$. These results suggested that upregulated miR-185 expression in GC cells may promote apoptosis. 
A
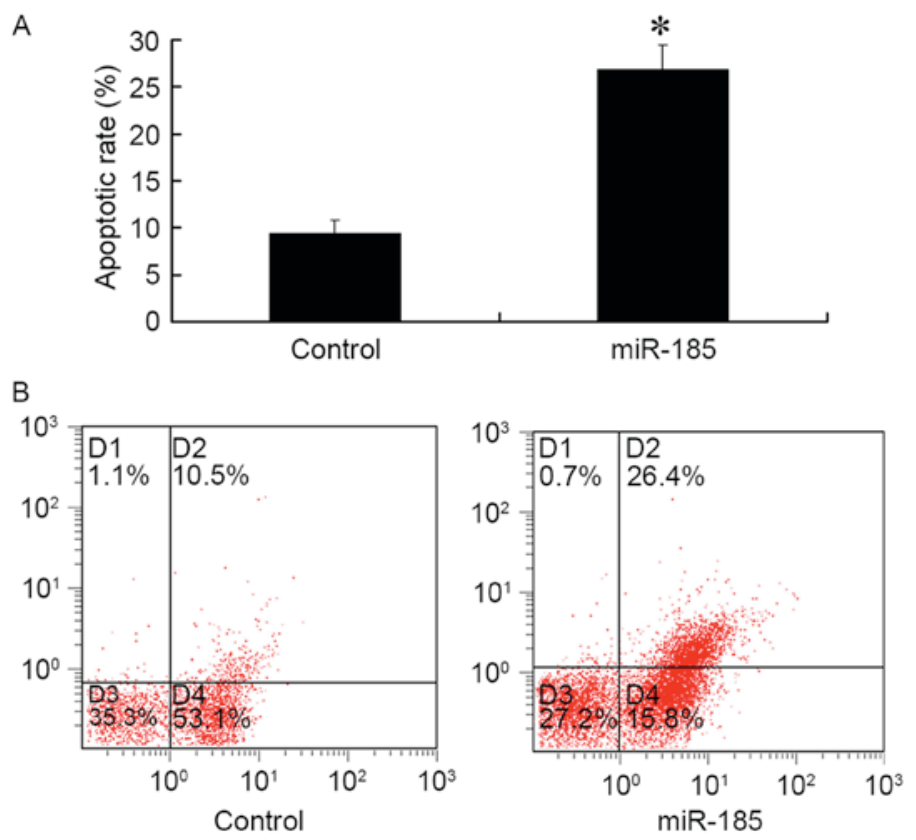

Figure 3. Effects of miR-185 mimics on the apoptotic rate of MGC803 cells, as determined by flow cytometry. A total of 48 h post-transfection of MCG803 cells with $80 \mathrm{nM}$ miR-185 mimics, the apoptotic rate was significantly increased compared with in the control group. (A) Apoptotic rate (\%) was presented as a histogram. (B) Original flow cytometry scatter plot is presented. Data are presented as the mean \pm standard deviation ( $\mathrm{n}=6 /$ group). ${ }^{*} \mathrm{P}<0.01 \mathrm{vs}$. the control group. miR-185, microRNA-185.
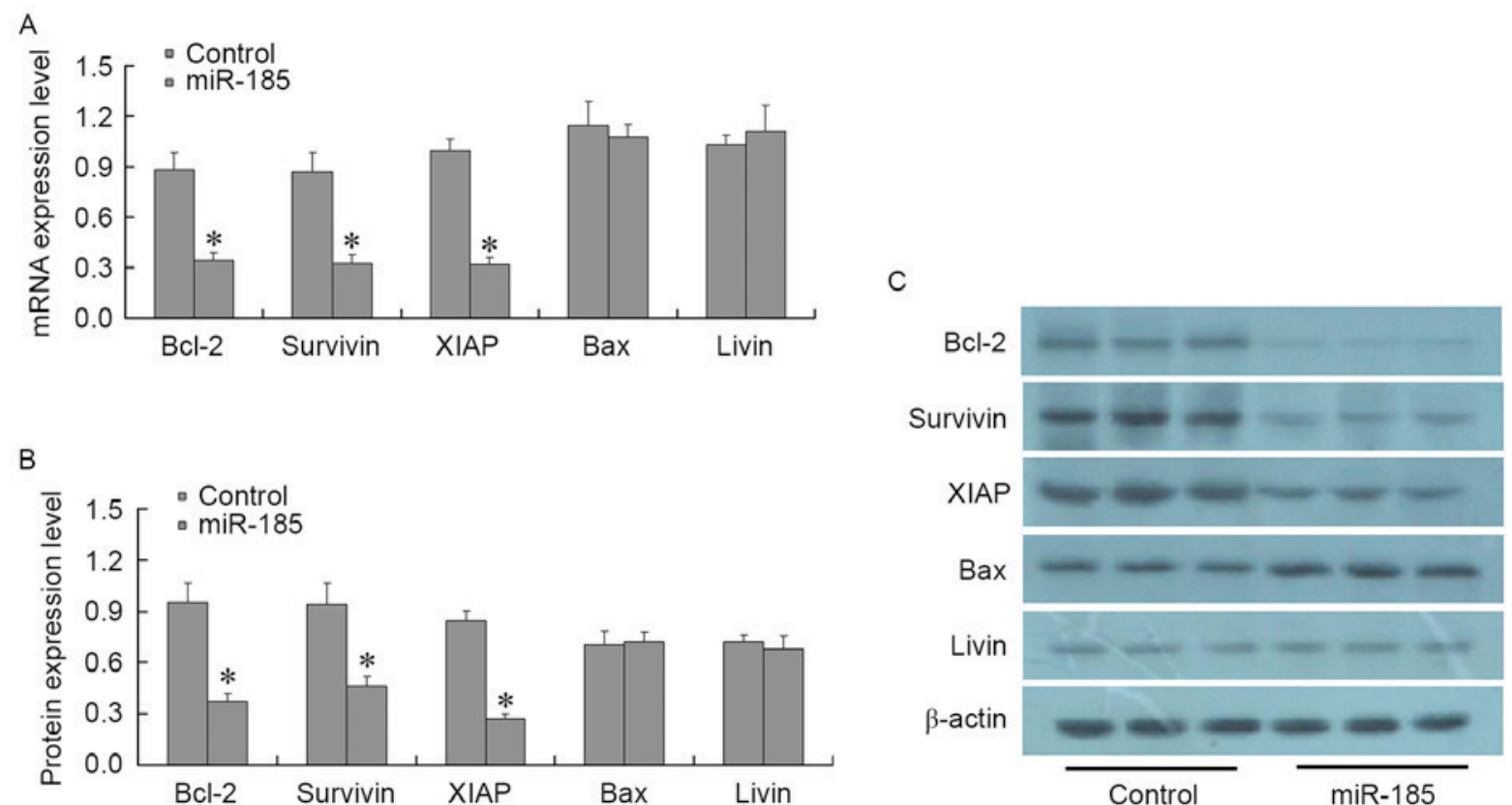

Figure 4. Effects of miR-185 mimics on the expression of apoptotic factors, Bcl-2, Bax, survivin, XIAP and livin, in MGC803 cells. A total of $48 \mathrm{~h}$ post-transfection of MCG803 cells with $80 \mathrm{nM}$ miR-185 mimics, (A) mRNA and (B and C) protein expression levels of Bcl-2, Bax, survivin, XIAP and livin were detected using quantitative polymerase chain reaction and western blotting, respectively. Bcl-2, survivin and XIAP were significantly decreased in miR-185 mimics-transfected MGC803 cells, whereas Bax and livin expressions was not significantly altered. ${ }^{*} \mathrm{P}<0.01 \mathrm{vs}$. the control group. miR-185, microRNA-185; Bcl-2, B-cell lymphoma 2; Bax, Bcl-2-associated X protein; XIAP, X-linked inhibitor of apoptosis protein.

Effects of miR-185 mimics on the expression of apoptotic factors in MGC803 cells. A total of 48 h post-transfection of MGC803 cells with $80 \mathrm{nM}$ miR-185 mimics, the expression levels of the following apoptosis-associated factors were detected: Bcl-2, Bax, survivin, XIAP, livin, caspase-3 and caspase-8. RT-qPCR and western blotting results demonstrated that post-transfection of MGC803 cells with miR-185 mimics, the expression levels of $\mathrm{Bcl}-2$, survivin and XIAP were significantly decreased $(\mathrm{P}<0.01)$, whereas the expression levels of Bax and livin were not significantly altered ( $P>0.01$; Fig. 4). In addition, the expression levels of caspase- 3 and caspase- 8 were significantly increased, as determined by RT-qPCR 
A

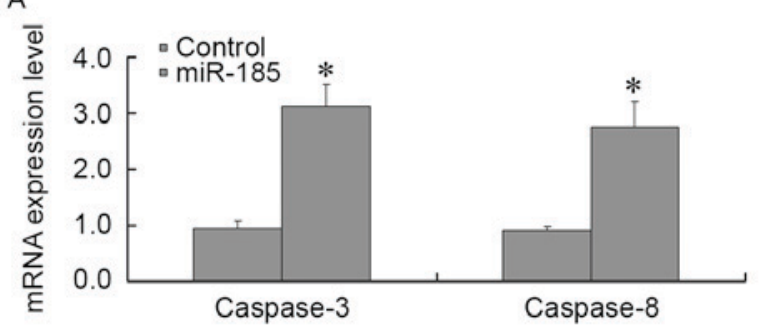

C

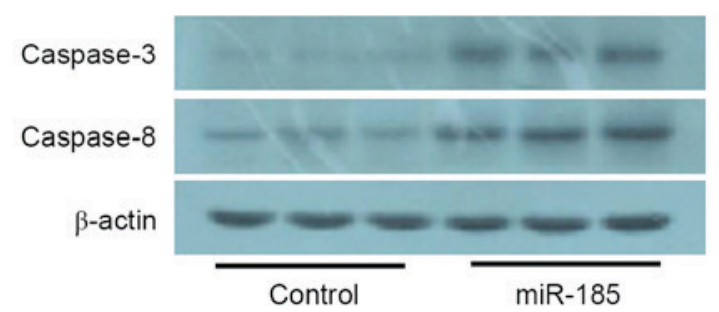

B

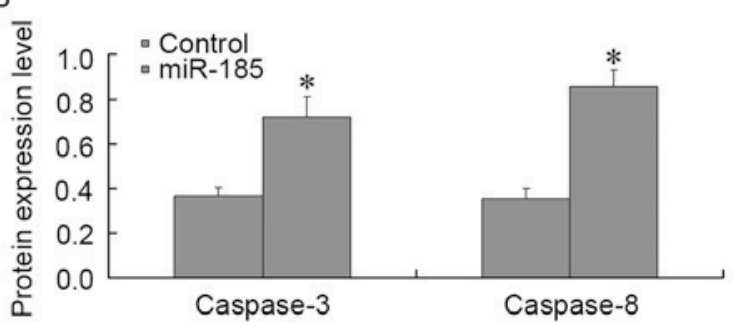

D

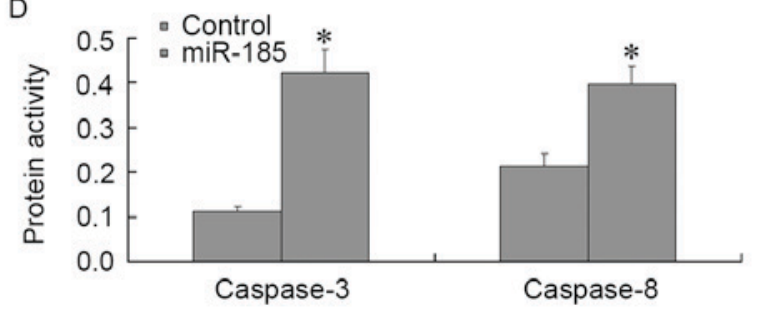

Figure 5. Effects of miR-185 mimics on the expression and activity of caspase-3 and caspase-8 in MGC803 cells. Cells were transfected with miR-185 mimics, and were then subjected to (A) quantitative polymerase chain reaction and (B and C) western blot analysis to detect the mRNA and protein expression levels of caspase- 3 and caspase-8. (D) Caspase- 3 and caspase- 8 activity in MGC803 cells. ${ }^{*} \mathrm{P}<0.01$ vs. the control group. miR-185, microRNA-185.

and western blotting $(\mathrm{P}<0.01$; Fig. $5 \mathrm{~A}-\mathrm{C})$. The results of a spectrophotometric analysis indicated that caspase-3 and caspase- 8 activity was significantly increased in MGC803 cells post-transfection with miR-185 mimics ( $\mathrm{P}<0.01$; Fig. 5D). These results suggested that, in GC cells, miR-185 may exert an inhibitory effect on anti-apoptotic factors, such as Bcl-2, survivin and XIAP. In addition, miR-185 may increase the expression and activity of core apoptotic genes caspase-3 and caspase-8, thus promoting apoptosis of GC cells.

\section{Discussion}

Although the worldwide incidence of GC has decreased in recent years, there remains a high incidence in Asia $(23,24)$, which seriously endangers the health of the population. Compared with normal cells, GC cells exhibit increased proliferation, angiogenesis, invasion and metastasis, reduced apoptosis, and immune evasion. Various molecules at various stages contribute to the development and progression of GC. Previous studies have investigated the associated genes and signaling pathways; however, the regulatory mechanism underlying GC remains unclear $(25,26)$.

miRNAs are a class of widely distributed, single-stranded, non-protein coding RNAs, 22 nucleotides in length. The main function of miRNAs is to inhibit the expression of downstream genes (27-31). It has previously been confirmed that miRNAs are closely associated with GC, and various miRNAs, such as miR-21, let-7 and miR-27, are invovled in invasion and metastasis of GC (32-34). miR-185 is a newly discovered miRNA, which is closely associated with numerous malignancies. Zhi et al reported that miR-185 exhibits tumor-suppressing activity; patients with hepatocellular carcinoma with low miR-185 expression had a low survival rate and short survival period (35). In addition, miR-185 has been revealed to be abnormally expressed in various malignancies, and is involved in the proliferation, invasion and metastasis of tumors, as well as the resistance of endometrial cancer cells to cisplatin (19-21). The present study indicated that miR-185 expression was significantly reduced in GC tissues and cell lines, thus suggesting that miR-185 is associated with GC. miR-185 was upregulated in GC cells post-transfection with miR-185 mimics, after which the viability of tumor cells was significantly reduced, suggesting that miR-185 may serve a role in GC cells by inhibiting proto-oncogenes, including tripartite motif-containing protein 29 , and zinc finger protein SNAI1 and $2(36,37)$. Therefore, miR-185 may be considered a potential novel target for GC biotherapy.

The detailed mechanism of action of miR-185 in GC remains unclear. Li et al demonstrated that miR-185 was able to induce apoptosis of prostate cancer cells (33); however, the association between miR-185 and GC cell apoptosis remains unclear. The present study confirmed that following upregulation of miR-185 expression in GC cells, the apoptotic rate was significantly increased; consequently, it was hypothesized that miR-185 may promote apoptosis by regulating the expression of apoptosis-associated factors. Therefore, the expression of apoptosis-associated factors were detected.

GC cells have a marked resistance to apoptosis, and disturbance of apoptotic regulation is an important mechanism underlying the progression of GC. Therefore, it is of great significance to explore the apoptotic mechanism of GC cells, so as to research the pathogenesis and potential treatment strategies of GC. The present study analyzed the alterations in the expression of apoptosis-associated factors post-transfection with miR-185 mimics, thus providing a basis for analyzing the mechanism of miR-185 in GC cells. $\mathrm{Bcl}-2 / \mathrm{Bax}$, which are important members of the mitochondrial pathway, can be combined into dimers. Alterations in the proportion of these dimers may lead to changes in the apoptotic ability of GC cells $(38,39)$. Survivin is an important member in the inhibitor of apoptosis protein family, which directly inhibits caspase family members, enhancing tumor 
cell resistance to apoptosis (11). XIAP may inhibit caspase-3 and -7 by inhibiting the death receptor and mitochondrial pathways $(40,41)$, thus serving a role in apoptotic suppression. Livin has an anti-apoptotic role via activation of the c-Jun $\mathrm{N}$-terminal kinase 1 signal transduction pathway, and can also directly inhibit caspase-3 or inhibit apoptosis by inhibiting caspase-9 $(42,43)$. Caspase-3 and -8 , as core apoptotic genes, can directly promote apoptosis $(12,44)$. The present study demonstrated that when miR-185 expression is upregulated in GC cells, the expression levels of Bcl-2, survivin and XIAP were significantly decreased, whereas caspase- 3 and caspase- 8 expression and activity were significantly increased, thus suggesting that miR-185 may activate caspase- 3 and caspase- 8 by inhibiting the expression of Bcl-2, survivin and XIAP, thus serving a role in promoting apoptosis. However, the underlying molecular mechanisms require further investigation.

In conclusion, the present study indicated that miR-185 expression in GC tissues and cell lines was significantly decreased. Upregulation of miR-185 was able to suppress the viability of GC cells and to increase their apoptotic rate by regulating apoptosis-associated genes. These results suggested that miR-185 may be instrumental in GC cell apoptosis, and may be considered a potential novel target in human GC biotherapy.

\section{References}

1. Sugano K: Screening of gastric cancer in Asia. Best Pract Res Clin Gastroenterol 29: 895-905, 2015.

2. Nishizawa M, Seshimo A, Miyake K, Amano K and Kameoka S: Usefulness of the TRC method in the peritoneal washing cytology for gastric cancer. Hepatogastroenterology 61: 240-244, 2014.

3. Li Y, Tan BB, Zhao Q, Fan LQ, Wang D and Liu Y: ZNF139 promotes tumor metastasis by increasing migration and invasion in human gastric cancer cells. Neoplasma 61: 291-298 2014.

4. Katanoda K, Matsuda T, Matsuda A, Shibata A, Nishino Y, Fujita M, Soda M, Ioka A, Sobue T and Nishimoto H: An updated report of the trends in cancer incidence and mortality in Japan. Jpn J Clin Oncol 43: 492-507, 2013.

5. Naito Y, Uchiyama K, Kinoshita Y, Fukudo S, Joh T, Suzuki H, Takahashi S, Ueno F, Fujiwara Y, Arakawa T, et al: A questionnaire-based survey on screening for gastric and colorectal cancer by physicians in East Asian countries in 2010. Digestion 86: 94-106, 2012.

6. Wang YJ, Liu JZ, Lv P, Dang Y, Gao JY and Wang Y: Long non-coding RNA CCAT2 promotes gastric cancer proliferation and invasion by regulating the E-cadherin and LATS2. Am J Cancer Res 6: 2651-2660, 2016.

7. Sun Y, Zhang D, Mao M, Lu Y and Jiao N: Roles of p38 and JNK protein kinase pathways activated by compound cantharidin capsules containing serum on proliferation inhibition and apoptosis of human gastric cancer cell line. Exp Ther Med 14: 1809-1817, 2017.

8. Jia S, Qu T, Feng M, Ji K, Li Z, Jiang W and Ji J: Association of Wnt1-inducible signaling pathway protein-1 with the proliferation, migration and invasion in gastric cancer cells. Tumour Biol 39: 1010428317699755, 2017.

9. Liu YY, Chen ZH, Peng JJ, Wu JL, Yuan YJ, Zhai ET, Cai SR, He YL and Song W: Up-regulation of long non-coding RNA XLOC_010235 regulates epithelial-to-mesenchymal transition to promote metastasis by associating with Snail1 in gastric cancer. Sci Rep 7: 2461, 2017.

10. Zhu M, Zhou X, Du Y, Huang Z, Zhu J, Xu J, Cheng G, Shu Y, Liu P, Zhu W and Wang T: miR-20a induces cisplatin resistance of a human gastric cancer cell line via targeting CYLD. Mol Med Rep 14: 1742-1750, 2016.

11. Wang QP, Wang Y, Wang XD, Mo XM, Gu J, Lu ZY, Pan ZL and Zhu YX: Survivin up-regulates the expression of breast cancer resistance protein (BCRP) through attenuating the suppression of $\mathrm{p} 53$ on NF- $\mathrm{KB}$ expression in MCF-7/5-FU cells. Int J Biochem Cell Biol 45: 2036-2044, 2013.
12. Wittkopf N, Günther C, Martini E, He G, Amann K, He YW, Schuchmann M, Neurath MF and Becker C: Cellular FLICE-like inhibitory protein secures intestinal epithelial cell survival and immune homeostasis by regulating caspase- 8 . Gastroenterology 145: 1369-1379, 2013.

13. Sikdar S, Mukherjee A, Ghosh S and Khuda-Bukhsh AR: Condurango glycoside-rich components stimulate DNA damage-induced cell cycle arrest and ROS-mediated caspase-3 dependent apoptosis through inhibition of cell-proliferation in lung cancer, in vitro and in vivo. Environ Toxicol Pharmacol 37: 300-314, 2014.

14. Hayakawa Y, Hirata Y, Sakitani K, Nakagawa H, Nakata W, Kinoshita H, Takahashi R, Takeda K, Ichijo H, Maeda S and Koike K: Apoptosis signal-regulating kinase-1 inhibitor as a potent therapeutic drug for the treatment of gastric cancer. Cancer Sci 103: 2181-2185, 2012.

15. Korbakis D and Scorilas A: Treatment of gastric cancer cells with 5-fluorouracil/leucovorin and irinotecan induces distinct alterations in the mRNA expression of the apoptosis-related genes, including the novel gene BCL2L12. Tumour Biol 30: 100-107, 2009.

16. Zhuo Z, Zhang L, Mu Q, Lou Y, Gong Z, Shi Y, Ouyang G and Zhang Y: The effect of combination treatment with docosahexaenoic acid and 5-fluorouracil on the mRNA expression of apoptosis-related genes, including the novel gene BCL2L12, in gastric cancer cells. In Vitro Cell Dev Biol Anim 45: 69-74, 2009.

17. Li Q, Wang JX, He YQ, Feng C, Zhang XJ, Sheng JQ and Li PF: MicroRNA-185 regulates chemotherapeutic sensitivity in gastric cancer by targeting apoptosis repressor with caspase recruitment domain. Cell Death Dis 24: e1197, 2014.

18. Wu XL, Cheng B, Li PY, Huang HJ, Zhao Q, Dan ZL, Tian DA and Zhang P: MicroRNA-143 suppresses gastric cancer cell growth and induces apoptosis by targeting COX-2. World J Gastroenterol 19: 7758-7765, 2013

19. Li X, Chen YT, Josson S, Mukhopadhyay NK, Kim J, Freeman MR and Huang WC: MicroRNA-185 and 342 inhibit tumorigenicity and induce apoptosis through blockade of the SREBP metabolic pathway in prostate cancer cells. PLoS One 8: e70987, 2013.

20. Qu F, Cui X, Hong Y, Wang J, Li Y, Chen L, Liu Y, Gao Y, Xu D and Wang Q: MicroRNA-185 suppresses proliferation, invasion, migration, and tumorigenicity of human prostate cancer cells through targeting androgen receptor. Mol Cell Biochem 377: 121-130, 2013.

21. Xiang Y, Ma N, Wang D, Zhang Y, Zhou J, Wu G, Zhao R, Huang H, Wang X, Qiao Y, et al: miR-152 and miR-185 co-contribute to ovarian cancer cells cisplatin sensitivity by targeting DNMT1 directly: A novel epigenetic therapy independent of decitabine. Oncogene 33: 378-386, 2014.

22. Livak KJ and Schmittgen TD: Analysis of relative gene expression data using real-time quantitative PCR and the 2(-Delta Delta C(T)) method. Methods 25: 402-408, 2001.

23. Kamangar F, Dores GM and Anderson WF: Patterns of cancer incidence, mortality, and prevalence across five continents: Defining priorities to reduce cancer disparities in different geographic regions of the world. J Clin Oncol 24: 2137-2150, 2006.

24. Li Y, Tan BB, Zhao Q, Fan LQ, Liu Y and Wang D: Regulatory mechanism of ZNF139 in multi-drug resistance of gastric cancer cells. Mol Biol Rep 41: 3603-3610, 2014

25. Zhao LY, Tong DD, Xue M, Ma HL, Liu SY, Yang J, Liu YX, Guo B, Ni L, Liu LY, et al: MeCP2, a target of miR-638, facilitates gastric cancer cell proliferation through activation of the MEK1/2-ERK1/2 signaling pathway by upregulating GIT1. Oncogenesis 6: e368, 2017.

26. Lee H, Saini N, Parris AB, Zhao M and Yang X: Ganetespib induces $\mathrm{G} 2 / \mathrm{M}$ cell cycle arrest and apoptosis in gastric cancer cells through targeting of receptor tyrosine kinase signaling. Int J Oncol 51: 967-974, 2017.

27. Xu X, Wu J, Li S, Hu Z, Xu X, Zhu Y, Liang Z, Wang X, Lin Y, Mao Y, et al: Downregulation of microRNA-182-5p contributes to renal cell carcinoma proliferation via activating the AKT/FOXO3a signaling pathway. Mol Cancer 13: 109, 2014.

28. Wang HY, Shen J, Jiang CP and Liu BR: How to explain the contradiction of microRNA 200c expression and survival in solid tumors? A meta-analysis. Asian Pac J Cancer Prev 15: 3687-3690, 2014

29. Li W, Jin X, Deng X, Zhang G, Zhang B and Ma L: The putative tumor suppressor microRNA-497 modulates gastric cancer cell proliferation and invasion by repressing eIF4E. Biochem Biophys Res Commun 449: 235-240, 2014. 
30. Yuan W, Xiaoyun H, Haifeng Q, Jing L, Weixu H, Ruofan D, Jinjin Y and Zongji S: MicroRNA-218 enhances the radiosensitivity of human cervical cancer via promoting radiation induced apoptosis. Int J Med Sci 11: 691-696, 2014.

31. Sun Z, Zhang Z, Liu Z, Qiu B, Liu K and Dong G: MicroRNA-335 inhibits invasion and metastasis of colorectal cancer by targeting ZEB2. Med Oncol 31: 982, 2014.

32. Yang SM, Huang C, Li XF, Yu MZ, He Y and Li J: miR-21 confers cisplatin resistance in gastric cancer cells by regulating PTEN. Toxicology 306: 162-168, 2013.

33. Li ZH, Pan XM, Han BW, Guo XM, Zhang Z, Jia J and Gao LB: A let-7 binding site polymorphism rs712 in the KRAS 3' UTR is associated with an increased risk of gastric cancer. Tumour Biol 34: 3159-3163, 2013.

34. Zhao X, Yang L and Hu J: Down-regulation of miR-27a might inhibit proliferation and drug resistance of gastric cancer cells. J Exp Clin Cancer Res 30: 55, 2011.

35. Zhi Q, Zhu J, Guo X, He S, Xue X, Zhou J, Hu B, Li H, Chen S, Zhao $\mathrm{H}$ and Kuang Y: Metastasis-related miR-185 is a potential prognostic biomarker for hepatocellular carcinoma in early stage. Biomed Pharmacother 67: 393-398, 2013.

36. Qiu F, Xiong JP, Deng J and Xiang XJ: TRIM29 functions as an oncogene in gastric cancer and is regulated by miR-185. Int J Clin Exp Pathol 8: 5053-5061, 2015.

37. Yoon JH, Choi WS, Kim O, Choi BJ, Nam SW, Lee JY and Park WS: Gastrokine 1 inhibits gastric cancer cell migration and invasion by downregulating RhoA expression. Gastric Cancer 20: 274-285, 2017.

38. Golestani Eimani B, Sanati MH, Houshmand M, Ataei M, Akbarian $\mathrm{F}$ and Shakhssalim N: Expression and prognostic significance of bcl-2 and bax in the progression and clinical outcome of transitional bladder cell carcinoma. Cell J 15: 356-363, 2014.
39. Wu S, Liu B, Zhang Q, Liu J, Zhou W, Wang C, Li M, Bao S and Zhu R: Dihydromyricetin reduced Bcl-2 expression via $\mathrm{p} 53$ in human hepatoma HepG2 cells. PLoS One 8: e76886, 2013.

40. Li S, Sun J, Yang J, Zhang L, Wang L, Wang X and Guo Z: XIAP expression is associated with pancreatic carcinoma outcome. Mol Clin Oncol 1: 305-308, 2013.

41. Chui YL, Ma CH, Li W, Xu Z, Yao Y, Lin FK, Chan JY and Lee KK: Anti-apoptotic protein BRE/BRCC45 attenuates apoptosis through maintaining the expression of caspase inhibitor XIAP in mouse Lewis lung carcinoma D122 cells. Apoptosis 19: 829-840, 2014.

42. Xu M, Xia LP, Fan LJ, Xue JL, Shao WW and Xu D: Livin and caspase-3 expression are negatively correlated in cervical squamous cell cancer. Eur J Gynaecol Oncol 34: 152-155, 2013.

43. Yang D, Song X, Zhang J, Ye L, Wang S, Che X, Wang J, Zhang $\mathrm{Z}$ and Wang L: Suppression of livin gene expression by siRNA leads to growth inhibition and apoptosis induction in human bladder cancer T24 cells. Biosci Biotechnol Biochem 74: 1039-1044, 2010

44. Sikdar S, Mukherjee A, Ghosh S and Khuda-Bukhsh AR: Condurango glycoside-rich components stimulate DNA damage-induced cell cycle arrest and ROS-mediated caspase-3 dependent apoptosis through inhibition of cell-proliferation in lung cancer, in vitro and in vivo. Environ Toxicol Pharmacol 37: 300-314, 2014. 